\title{
LA NARRATIVA DE LO INUSUAL EN LA LITERATURA MEXICANA: UN ESTUDIO SOBRE LOS INGRÁVIDOS Y DESIERTO SONORO DE VALERIA LUISELLI ${ }^{1}$
}

\author{
SARA NúÑEZ DE LA FUENTE \\ Universidad de León \\ Universidad Isabel I (Burgos) \\ sara.nunez@ui1.es
}

Recibido: 28-08-2020

Aceptado: 29-04-2021

(c) (1)

RESUMEN

Desde hace algunos años, se comienza a vislumbrar entre los géneros narrativos de lo insólito una serie de escritoras mexicanas que presentan una nueva modalidad discursiva a la que Carmen Alemany Bay ha denominado «narrativa de lo inusual». En este artículo se observan bajo dicha categoría las novelas Los ingrávidos y Desierto sonoro, de Valeria Luiselli, poniendo el foco fundamentalmente en los planos espaciotemporales y la intertextualidad. A lo largo del análisis, se descubren una serie de elementos fantásticos de carácter metafórico que constituyen las bases de este tipo de narrativa.

Palabras Clave: Valeria Luiselli; Los ingrávidos; Desierto sonoro; literatura mexicana; narrativa de lo inusual.

THE NARRATIVE OF THE UNUSUAL IN MEXICAN LITERATURE: A STUDY OF FACES IN THE CROWD AND LOST CHILDREN ARCHIVE BY VALERIA LUISELLI

ABstract

For some years now, we start to see in unrealistic narrative genres a series of Mexican women writers who present a new discursive modality that Carmen Alemany Bay has

1 Este trabajo se inscribe en el proyecto de investigación Estrategias y figuraciones de lo insólito. Manifestaciones del monstruo en la narrativa en lengua española (de 1980 a la actualidad) (PGC2018-093648-B-100). 
called «narrative of the unusual». In this paper the novels Faces in the Crowd and Lost Children Archive by Valeria Luiselli are observed under this category focusing fundamentally on spacetime and intertextual forms. Throughout this analysis, we can see elements of fantastic literature from a metaphorical perspective which constitute the foundations of this narrative category.

Keywords: Valeria Luiselli; Faces in the Crowd; Lost Children Archive; Mexican literature; narrative of the inusual.

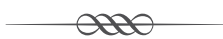

1. INTRODUCCIÓN: LA NARRATIVA DE LO INUSUAL Y OTRAS MODALIDADES DE LO INSÓLITO

Desde hace algunos años, se comienza a vislumbrar entre los géneros narrativos de lo insólito una serie de escritoras mexicanas que, sin mostrar una identidad consciente de grupo, presentan una nueva modalidad discursiva colindante con lo fantástico, el realismo mágico, lo maravilloso y otras formas narrativas que se oponen al realismo. Carmen Alemany Bay (2016: 132) observó coherencias entre ellas y propuso estudiarlas bajo la categoría de la «narrativa de lo inusual». El corpus de estudio que maneja la autora incluye narradoras mexicanas nacidas a partir de los sesenta y que han publicado sus principales obras en el siglo xxI, fundamentalmente novelas cortas y relatos, pues es en estos géneros donde la narrativa de lo inusual se desarrolla con mayor fluidez.

Entre el amplio conjunto de narradoras mexicanas que se estudian bajo esta categoría, y entre las que se encuentra Valeria Luiselli (1983), señalamos, a modo de ejemplo, a Patricia Laurent Kullick con El camino de Santiago (2003), Cecilia Eudave con Bestiaria vida (2008), Paulette Jonguitud Acosta con Moho (2010) o Lourdes Meraz con Los abismos de la piel (2013). No obstante, también se observan características propias de lo inusual fuera de las fronteras mexicanas; nos referimos, en este sentido, a las argentinas Samanta Schweblin, Mariana Enríquez o Ariana Harwicz, también a la peruana Claudia Ulloa o a algunos relatos de la ecuatoriana Solange Rodríguez Pappe (Alemany Bay, 2019: 314).

Aunque a lo largo del artículo se analizan las principales características de la narrativa de lo inusual, resulta pertinente exponer en este apartado una breve presentación que recoja algunos de sus rasgos narrativos más distintivos. Todas las narradoras citadas comparten un mismo contexto sociocultural y pre- 
ocupaciones estéticas similares en las que se distinguen mecanismos como la fragmentariedad, la intertextualidad, la reescritura de textos canónicos o la metaficción: «Amén de otros rasgos como la tendencia a la prosa poética o la hibridación entre la ficción y los elementos autobiográficos» (Alemany Bay, 2018: 10). La mayoría de estas obras están escritas en primera persona desde una perspectiva subjetiva; una narrativa de tipo personal que manifiesta episodios esquizoides, desdoblamientos, reflexiones y divagaciones.

Este tipo de novelas y relatos parecen derivar de la llamada posmodernidad, pues en ellos se observa una realidad cotidiana compleja donde los personajes no encuentran su lugar en el mundo. Esa cotidianidad se materializa en el texto literario a través de un discurso narrativo que fluctúa entre lo real y lo fantástico. Es decir, la narrativa de lo inusual presenta alegorías, comparaciones o fábulas que, sin llegar a lo fantástico, ofrecen una representación inusual de la realidad: «lo que había parecido fantástico era una manera de codificar una realidad íntima dolorosa y externa incomprensible que requiere de tropos alucinados, hiperbólicos o desgarradores para poder ser expresada en un ejercicio que ayuda a las narradoras a recomponer su identidad» (García-Valero, 2019: 336).

A diferencia de los relatos de tradición fantástica, en la narrativa de estas autoras la oscilación entre lo posible y lo imposible no produce extrañamiento ni inquietud en el lector, pues no se observa una apertura a nuevas realidades a partir de la vida cotidiana. Aunque los personajes muestran incertidumbre y vacilaciones, son conscientes de estar afincados en la realidad, lo que no impide que transiten por universos complejos derivados de una realidad alterada por la imaginación.

Para referirnos a lo inusual como una modalidad narrativa diferenciada dentro de las distintas categorías que constituyen lo insólito, resulta necesario abordarla en relación con las demás modalidades. Entre ellas destacan lo extraño, lo fantástico, lo maravilloso y el realismo mágico. García-Valero (2019) advierte que en general lo inusual se aproxima bastante al discurso de lo extraño, pues suceden cosas anómalas, se presenta un lenguaje alucinado que relaciona anécdotas de lo posible con otras de lo imposible y el lector duda si lo que se narra sucede en un mundo ficcional desarrollado por el texto o pertenece a la imaginación de sus personajes. Sin embargo, el autor se decanta por diferenciarlos debido, por un lado, a las diferentes estrategias lingüísticas que presentan ambas modalidades —en la estética de lo inusual abundan los tropos y las alegorías- y, por otro lado, a que el extrañamiento no resulta interesante para lo inusual del mismo modo que en los siglos XIX o xx, pues no se inspira en casos anómalos que quiebren las bases científicas, 
como enfermedades raras, experiencias de conciencia expandida o estados de trance que daban lugar a espacios oníricos, sino en una realidad actual que es vivida por los personajes como extraña en sí misma.

En relación con lo fantástico, David Roas señala que una de las condiciones básicas que configuran esta modalidad es la necesidad de ambientar los hechos insólitos en un mundo como el nuestro, es decir, un mundo regido por las mismas leyes naturales. El autor presenta como ejemplo de lo fantástico el fantasma que retorna del más allá para mostrarse ante los vivos «planteando con ello una transgresión absoluta de nuestros códigos sobre el funcionamiento de lo real» (2011: 46). Esta modalidad se aleja, por tanto, de lo inusual, ya que cruza la frontera de lo imposible. La narrativa de lo inusual tampoco coincide por completo con los relatos que se inscriben bajo la categoría de maravillosos. Roas (2011) indica que en este caso no se plantean confrontaciones entre lo posible y lo imposible, pues las hadas, los animales humanizados o los encantamientos son posibles en ese mundo maravilloso, por lo que los personajes y el narrador asumen los hechos sin cuestionarlos; el relato no trastorna su concepción de la realidad. Es decir, mientras que la narrativa de lo inusual recrea espacios cotidianos que reflejan nuestro mundo, lo maravilloso presenta mundos que se rigen por leyes naturales diferentes y en los que tienen cabida seres y acontecimientos que no suceden en nuestra realidad.

La última modalidad de literatura no mimética que señalamos, el realismo mágico, se remonta a 1925. El crítico de arte alemán Franz Roh acuñó este término para referirse a una nueva corriente pictórica que retomó la representación del mundo objetivo, pero no como copia fiel de la realidad, sino mostrando lo real desde una perspectiva mágica. Roh presenta como ejemplos las obras de Picasso, Beckmann, de Chirico, Derain y Carrà (Roas, 2011). Más adelante, el realismo mágico se manifestó en la literatura con autores como Bontempelli o Buzzati. Aunque muchos escritores europeos de los años 30 y 40 publicaron narraciones que se pueden observar desde la categoría del realismo mágico, los escritores hispanoamericanos son los que han aportado las mejores producciones al respecto. Un ejemplo representativo de este tipo de literatura lo constituye el cuento de Gabriel García Márquez «Un señor muy viejo con unas alas enormes» (1968). En esta modalidad de lo insólito, la irrupción de seres que se consideran imposibles desde las leyes naturales que rigen el mundo real es aceptada con normalidad por los personajes, pues acomodan lo extraño a alguna lógica basada en leyendas, religiones o fenómenos de la naturaleza. Además, el narrador contribuye a integrar lo real y lo irreal presentando los fenómenos insólitos como si fueran corrientes, de manera que el lector termina aceptándolos como algo natural. 
Sandro Abate llama la atención sobre la controversia entre quienes sostienen que el realismo mágico es una categoría dentro de las posibilidades de la literatura fantástica — como Flores, Maturo y Planells- y quienes consideran que no existe esa relación de subordinación —como Leal, Anderson Imbert o Chiampi- sino un nuevo proyecto estético que «surge de la síntesis entre lo verídico y lo sobrenatural» (1997: 151). Estos autores tienden además a limitar el uso del concepto al ámbito de la literatura hispanoamericana. Partiendo, como afirma Barrenechea, de que «lo fantástico es la subversión del orden racional con sentido problemático» (apud Abate, 1997: 151), Abate concluye que el realismo mágico presenta otros muchos y más peculiares rasgos que lo alejan de esta definición. El autor señala en este sentido que en las narraciones mágicorrealistas «no se subvierten los atributos de la realidad cotidiana ni aquellos que configuran el espacio y el tiempo» (1997: 151). Es decir, mientras que en la literatura fantástica se subvierte el orden racional, en el realismo mágico no existe esa problemática, ya que lo irreal aparece como parte de lo real y se disuelve el conflicto entre lo natural y lo sobrenatural.

García-Valero (2019) sostiene algunas diferencias fundamentales entre lo inusual y el realismo mágico. El autor advierte que lo inusual presenta en ocasiones entornos sobrenaturales, pero la mayoría de las veces se entienden como hipérboles de las protagonistas, o como alucinaciones y ensoñaciones. Otra diferencia significativa que señala es la ausencia de poder identitario colectivo en la narrativa de lo inusual: «No hay referencia a sustratos indígenas precolombinos ni sirven estos para sustentar los elementos sobrenaturales que puedan aparecer en la narrativa. Hay, de hecho, una presencia mayor de materiales míticos de raigambre europea» (García-Valero, 2019: 332), como los basiliscos y lobos que presenta Cecilia Eudave en Bestiaria vida o el minotauro que aparece de Los abismos de la piel de Lourdes Meraz, pero hasta ahora no ha incluido el quetzal o el amaru. No obstante, García-Valero (2019) advierte que en la narrativa de lo inusual sí se observa un carácter identitario significativo de tipo individualizador, pues las protagonistas se esfuerzan por hallar una identidad propia.

Después de presentar las principales características de la narrativa de lo inusual, y de compararla con otras modalidades de lo insólito con las que colinda, se va a estudiar esta nueva modalidad narrativa propuesta por Alemany Bay a través dos obras concretas de la escritora mexicana Valeria Luiselli - Los ingrávidos y Desierto sonoro-que comparten una serie de rasgos fundamentales como son el protagonismo femenino, el cuestionamiento constante de sus relaciones con los otros, las relaciones familiares conflictivas o la maternidad, y se 
pondrá el foco fundamentalmente en el espacio, el tiempo y la intertextualidad a modo de eje conductor.

Luiselli se presenta como una de las narradoras más jóvenes que contribuyen a la configuración de la narrativa de lo inusual, aunque no todos sus libros se pueden inscribir bajo dicha categoría. Su primera obra fue un libro de ensayos titulado Papeles falsos y publicado en 2010 en el que muestra temas de muy diverso orden, como los mapas, las bicicletas o los cementerios, y donde lo que prima es la particular mirada de la autora sobre las distintas realidades. Más adelante, en 2011, publicó su primera novela: Los ingrávidos. Ateniéndonos a las características de la narrativa de lo inusual que presenta Alemany Bay, dicha obra se presenta como la más susceptible de análisis bajo estas teorías. Dos años más tarde, publicaría su segunda novela, La historia de mis dientes, protagonizada por el cantador de subastas Gustavo Sánchez Sánchez. Aunque el corpus manejado por Alemany Bay está centrado en personajes femeninos, cabe señalar que esta obra presenta varios rasgos característicos de lo inusual, por ejemplo, hacer dudar al lector sobre si los hechos son reales o un producto de la imaginación del protagonista y también una narrativa de tipo personal que manifiesta las reflexiones y divagaciones del personaje (v. Luiselli, 2014).

En 2016 saldría a la luz su segundo libro de ensayos, Los niños perdidos, donde muestra un testimonio sobre la realidad de los menores migrantes que cruzan la frontera entre México y los Estados Unidos. Esta obra funcionaría como base para la publicación de su tercera novela en 2019 titulada Desierto sonoro. A pesar de que no se puede inscribir bajo la categoría de novela corta o cuento, que es la forma habitual que adquieren los relatos de lo inusual, sí comparte varias características con esta modalidad en general y también con Los ingrávidos en concreto, como la experimentación espaciotemporal en el nivel lingüístico y enunciativo, es decir, sin un objetivo explícitamente fantástico, por lo que se tomará como objeto de estudio en el siguiente apartado.

2. ANÁLISIS DE LOS INGRÁVIDOS Y DESIERTO SONORO DESDE LAS TEORÍAS DE LO INUSUAL: ESPACIO, TIEMPO E INTERTEXTUALIDAD

Durante la presentación en Berlín de la novela Los ingrávidos (2011), Valeria Luiselli afirmó, tal como atestigua la periodista Eva Usi, que en el libro no hay fantasmas, sino temporalidades que se cruzan, dos personas lectoras que de alguna manera se vislumbran. Declara asimismo que pensó mucho en cómo construir esas temporalidades y recordó los versos de Francisco de Quevedo 
«vivo en conversación con los difuntos / y escucho con mis ojos a los muertos» (1968: 105). Esta idea configura a lo largo de la trama la convivencia de personajes literarios del pasado con personajes vivos, que se relacionan a su vez con experiencias cotidianas inmediatas. Lo que le interesa a la escritora mexicana es, en definitiva, y como explicita ella misma, «poner a convivir en un mismo plano a esta multiplicidad de temporalidades que finalmente forman parte de nuestra experiencia» (Usi, 2013). Sin embargo, la contraportada del libro anuncia que «Los ingrávidos es una novela sobre existencias fantasmales».

La obra presenta dos voces narrativas fundamentales, una de ellas pertenece a una mujer del México contemporáneo que narra en forma de libro sus años de juventud como dictaminadora y traductora en una editorial de Nueva York, donde trata de convencer a White, el chief editor, para traducir y publicar al poeta mexicano Gilberto Owen. La otra voz narradora se corresponde con la de un Owen al borde de la muerte que recuerda su juventud a finales de los años veinte durante el Renacimiento de Harlem, donde participaba en la vida literaria neoyorkina junto a autores como Louis Zukofsky o Federico García Lorca. Los pasados de ambos narradores se cruzan en el espacio de los trenes subterráneos evocando el discurso de lo fantástico a través de alusiones más o menos explícitas a algunos de los motivos literarios que lo constituyen, como el fantasma o el doble:

El metro me acercaba a las cosas muertas; a la muerte de las cosas. Un día, mientras regresaba a mi casa en la línea uno desde el sur de la ciudad, volví a ver a Owen. Esta vez fue distinto (...) algo como un golpe interior, una certeza punzante de que estaba ante algo hermoso y a la vez terrible (...) se acercó por atrás otro tren y por unos instantes anduvo a la misma velocidad que el tren donde iba yo. Lo vi sentado, con la cabeza reclinada sobre la ventana del vagón. Y después nada. Su tren aceleró y pasaron frente a mis ojos, barridos y afantasmados, muchos otros cuerpos. Cuando otra vez hubo oscuridad detrás de la ventana vi contra el vidrio mi propia imagen difusa. Pero no era mi rostro; era mi rostro superpuesto al de él — como si su reflejo se hubiera quedado plasmado en el vidrio y ahora yo me reflejara dentro de ese doble atrapado en la ventana de mi vagón-(Luiselli, 2019a: 65).

Nicolas Licata señala que la originalidad de Luiselli consiste en encontrar la forma de fusionar «dos figuras de luenga tradición en la literatura fantástica, el Doble y el fantasma, que comparten el motivo común de arremeter contra la unidad de la personalidad humana» (2020: 82). En este fragmento de la novela se observa además que el discurso de lo fantástico se articula en torno a un espacio narrativo que se relaciona con el concepto de no lugar acuñado por el antropólogo francés Marc Augé en 1992, es decir, «un espacio que 
no puede definirse como espacio de identidad ni como relacional ni como histórico» (2000: 82), donde los puntos de tránsito, las ocupaciones provisionales y la apretada red de medios de transporte son también espacios habitados que configuran un mundo "prometido a la individualidad solitaria, a lo provisional y a lo efímero, al pasaje» (2000: 84). Como ejemplos de no lugares, Augé señala los aeropuertos, las estaciones ferroviarias, las grandes cadenas hoteleras o los supermercados, en definitiva, una red al servicio de «una comunicación tan extraña que a menudo no pone en contacto al individuo más que con una imagen de sí mismo» (2000: 85).

Como contrapunto al espacio narrativo del metro, que equiparamos al concepto de no lugar, Luiselli configura a lo largo del libro otros espacios que se articulan también en torno al tema de las existencias fantasmales y que abren paso asimismo al cruce de temporalidades. Si bien adquieren la categoría de urbanos, cabe señalar que, a diferencia de los no lugares, el lector se encuentra ante escenarios de apartamiento que inducen a la reflexión y al establecimiento de puentes con el pasado a través del recuerdo: «Me gustaban los cementerios, los parques y las azoteas de los edificios, pero sobre todo los cementerios. De algún modo vivía en un estado perpetuo de comunión con los muertos» (Luiselli, 2019a: 19).

Entre todos ellos, el que adquiere un peso más relevante en la historia es la azotea del edificio donde había vivido Owen durante su estancia en Nueva York. Cuando la editora se detiene ante la fachada, se da cuenta de que está entrando un vecino, así que aprovecha para colarse por la puerta y subir las escaleras hasta el último piso. Tras leer y fumar durante horas, decide volver a casa y en ese momento descubre en un rincón de la azotea un pequeño árbol seco en una maceta cuyas características le recuerdan a la que describe Owen a Villaurrutia: «Vivo en Morningside Av. 63. En la ventana derecha hay una maceta que parece una lámpara» (Luiselli, 2019a: 31). Aunque era imposible que esa maceta fuera la misma a la que se refería el poeta en su carta, la editora observa el encuentro del objeto como una señal que estaba esperando. Cuando se dirige hacia la puerta cargando con la maceta, se da cuenta de que no hay cerrojo por fuera y no encuentra la manera de abrirla, por lo que se ve obligada a pasar la noche en la azotea: «ésa fue la primera noche que tuve que pasar con el fantasma de Gilberto Owen. En la vida real no hay giros de tuerca, pero fue a partir de entonces que comencé, poco a poco, a existir como habitada por otra vida posible que no era la mía, pero que basta imaginar para abandonarme a ella por completo» (Luiselli, 2019a: 33). García-Valero (2020) desarrolla en este sentido la noción del «otro-yo lírico» para explicar cómo la 
presencia de otro ser dentro del protagonista de lo inusual presiona hacia el efecto lírico que suelen tener estos textos, y expone como ejemplo al personaje principal de Odio, de la escritora mexicana Adriana Díaz Enciso (1964), quien siente miedo de otra persona que parece habitarla. El autor señala que las irrupciones de esa alteridad «son interferencias en un discurso ya de por sí discontinuo que balbucea el anhelo de las protagonistas de tener un lugar en el mundo comprensible y amigo» (García-Valero, 2020: 29).

Asimismo, el carácter de la azotea como espacio fantasmal o, siendo más precisos, como representación física del espacio psicológico en el que se produce la percepción de otra realidad a través de la imaginación, se relaciona con la reflexión sobre los espacios elevados que expone Luiselli en su tercera novela, Desierto sonoro, pues en este caso los presenta igualmente como lugares que promueven el ejercicio del pensamiento:

Cuando era adolescente, tenía una amiga que siempre que tenía que tomar una decisión o entender un problema difícil buscaba un lugar elevado. Una azotea, un puente, una montaña si la había, cualquier tipo de promontorio. Su teoría era que no se puede tomar una buena decisión relevante sobre ningún asunto si no se siente esa vertiginosa claridad que sólo las alturas procuran (2019b: 71).

En definitiva, el encuentro de la planta en la azotea del edificio donde había vivido Owen se erige como el motor del cruce de temporalidades entre la editora y el poeta mexicano muerto en 1952, que avanzará hacia los encuentros fugaces en el metro y la posterior desaparición de la voz narradora femenina sobre la que se va imponiendo la del propio Owen, que también irá desapareciendo. Resulta pertinente hacer referencia aquí a uno de los valores simbólicos que tradicionalmente se han asociado a los árboles. Cirlot indica que «el árbol representa, en el sentido más amplio, la vida del cosmos, su densidad, crecimiento, proliferación, generación y regeneración. Como vida inagotable equivale a inmortalidad» (2018: 89), por lo que no resulta extraño que el cruce temporal entre presente y pasado, entre la editora y la representación fantasmal del poeta, se origine a partir de este símbolo. Más adelante el mismo Owen advierte: «un día se me murió el naranjo (...) Me puso tan triste su repentina muerte seca, me pareció tan profética a su manera, que subí las escaleras de mi edificio hasta la azotea y ahí mero lo dejé» (Luiselli, 2019a: 111).

Sin embargo, varios elementos narrativos relacionados con la planta impiden interpretar la novela como una historia sobre personajes inmortales o poderes adivinatorios, y tampoco cabe observar el cruce de temporalidades como un fenómeno que altere los parámetros de la vida real, es decir, como un 
acontecimiento vinculado con la literatura fantástica. Nos encontramos, por tanto, ante una novela que se puede observar desde las teorías de la narrativa de lo inusual que propone Alemany Bay (2019) y que iremos desarrollando en este artículo. El hecho de que la narradora reconozca que esa maceta no podía haber pertenecido realmente a Owen aleja al objeto de la categoría de mágico o fantasmal que adquiriría en la tradición literaria fantástica, es decir, los encuentros entre la editora y el poeta no remiten al plano de lo imposible, sino que se dan en el plano psicológico de la protagonista.

Si bien la planta no se sitúa en el lado de lo imposible, sí adquiere un valor relevante como elemento narrativo que articula el discurso. La narradora registra notas sobre Owen en post-its amarillos y los va colocando entre las ramas del árbol seco. Cuando comienzan a caer por su propio peso, las recoge para escribir en ese mismo orden la vida del poeta. Esos pequeños textos se van sucediendo a medida que avanza el libro intercalándose con las voces narradoras de la editora y de Owen, lo que potencia el carácter fragmentario de la novela.

Observamos, en definitiva, que Luiselli emplea elementos narrativos que oscilan entre lo fantástico y la realidad, pero se impone lo segundo, es decir, nos encontramos ante una representación inusual de la realidad. Según García-Valero «la calidad de insólito que posee el texto [de lo inusual] se mantiene únicamente en el nivel lingüístico y enunciativo» (2019: 333). El espacio narrativo de la azotea se convierte así en un punto de intersección de diferentes planos temporales con la finalidad de experimentar con el lenguaje y el tiempo narrativos sin una intencionalidad explícitamente fantástica, como pone de manifiesto la propia autora en la presentación del libro en Berlín al afirmar que en Los ingrávidos no hay fantasmas.

Luiselli emplea el léxico de la tradición fantástica para crear una novela en la que las temporalidades se cruzan o donde los narradores van desapareciendo a medida que avanza la historia hasta convertirse en simples voces. Como la misma autora indica, esta idea parte de la reflexión sobre qué sucedería a todos los niveles con un personaje que siente que está desapareciendo frente al mundo, que se está afantasmando (Luiselli, 2011a). Y señala que su interés no se encuentra solo en qué características adquirirían las acciones cotidianas, sino también en explorar qué sucedería en el plano del lenguaje cuando alguien se está desintegrando.

Las voces narradoras de la novela se estructuran, por tanto, de forma que van perdiendo predominancia a medida que avanza la historia, sin que ello suponga la desintegración del personaje entendida desde una perspectiva fantástica. Hasta la página 64, observamos la voz de la editora que se desdobla en 
un presente en el que vive en México con su marido y sus dos hijos, a los que se refiere como el mediano y la bebé, y un pasado, el de sus años de juventud en Nueva York. En ninguno de los dos casos se muestran unos límites temporales precisos que permitan situar los hechos en un periodo determinado. Asimismo, la ficción que escribe sobre su pasado, la realidad presente y la ficción que se corresponde con la película que va a rodar su marido en Filadelfia, entran a menudo en conflicto, se confunden o se determinan mutuamente:

¿Cuándo te vas a Filadelfia?

La próxima semana.

¿Y por qué estás empacando desde ahora?

Porque eso escribiste. Dejaste tu computadora abierta y leí un fragmento. Pero es sólo una novela, nada existe (Luiselli, 2019a: 82).

A partir de la página 64, la voz femenina comienza a perder peso y se introduce la voz de Owen, que se divide a su vez en dos planos temporales distintos. Uno se corresponde con el final de su vida, mientras que en el otro narra su juventud a finales de los años veinte en Harlem, donde participaba de la vida literaria neoyorkina.

Toda esta multiplicidad de espacios, tiempos y narradores se presentan en pequeños fragmentos, breves y concisos, con diversas voces que se alternan y confunden en el espacio y el tiempo hasta desintegrarse progresivamente. Desde el comienzo de la novela, la narradora advierte de esta disposición narrativa: «Yo tengo una bebé y un niño mediano. No me dejan respirar. Todo lo que escribo es — tiene que ser- de corto aliento. Poco aire» (Luiselli, 2019a: 14). La misma autora declara en una entrevista sobre Los ingrávidos que ya venía explorando esa manera de escribir en corto aliento, como estampas o post-its, en su libro de ensayos Papeles falsos, aunque en este caso no había llegado tan lejos (Luiselli, 2011b). En ambos libros, aunque de forma más significativa en la novela, le interesaba desde un punto de vista narrativo cómo podrían ocurrir transiciones entre escenas muy distintas, e incluso narradas por distintas personas, pero donde hubiera un eco que persistiera al pasar de una otra.

Luiselli indica que algunas transiciones son fonéticas, y en este caso tal vez habría que leer en voz alta para percibirlas; otras consisten en la repetición de una imagen que procede de un fragmento anterior y se desarrolla en el siguiente. La escritora añade además otra justificación que tiene que ver con la construcción del personaje y a la que ya se ha hecho referencia en la cita anterior: la narradora tiene dos hijos pequeños y continuamente está luchando contra una serie de fuerzas que le impiden escribir y solo encuentra pequeños 
lapsos de tiempo que se materializan en esa serie de estampas o post-its. Sin embargo, cuando narra Owen, los textos son bastante más largos porque esa inmediatez que Luiselli necesita para la narradora deja de ser relevante para la construcción del personaje del poeta, a quien dedica fragmentos que se podrían considerar capítulos cortos. Tanto las frases breves como las transiciones fonéticas revelan, en definitiva, una de las claves estéticas de lo inusual: «las restricciones del lenguaje "realista" estándar y la necesidad de acudir a un lirismo mezclado con lo insólito para que el personaje intente explicarse» (García-Valero, 2019: 327).

Siguiendo con las características de la narrativa de lo inusual, resulta pertinente destacar todas aquellas que se presentan de forma significativa en la novela de Luiselli. Como se ha podido comprobar, lo insólito se combina a lo largo del libro con el realismo cotidiano, en este caso el de dos personajes que viven en Nueva York durante un tiempo, pero en diferentes épocas. Asimismo, en consonancia con otras obras literarias que se pueden observar desde la categoría de lo inusual, Luiselli juega con efectismos, hace percibir al lector la sensación de estar ante algo insólito que en realidad no lo es. Son importantes desde esta perspectiva la fragmentación, las múltiples historias y el aparente caos.

En relación con las múltiples historias, es importante hacer referencia a la doble personalidad de la tradición fantástica, aunque desde la perspectiva de lo inusual adquiere otras formas y significaciones. El motivo literario del doble se vincula en este caso con las voces narrativas desdobladas y con las diferentes facetas o vidas que experimenta un individuo: «Le pude haber dicho que me iba porque era incapaz de sostener y habitar los mundos que yo misma fabricaba, que yo también tenía una cicatriz que me partía la cara en dos» (Luiselli, 2019a: 86). Además, en la narrativa de lo inusual el doble se relaciona con la necesidad de desprenderse de uno mismo para comprenderse y se presenta como una crítica al sentido unitario de la racionalidad que caracteriza la modernidad. Nos encontramos, en definitiva, ante una realidad alterada por la imaginación de los protagonistas, es decir, una reinterpretación de la realidad. Se trata de la representación de un mundo interiorizado donde lo que sucede no tiene por qué funcionar como en la cotidianidad; las fronteras entre el mundo interiorizado y la vida cotidiana se disuelven sin que ello plantee ningún problema.

Asimismo, en el caso de Los ingrávidos, como sucede en otras novelas que se caracterizan por la narrativa de lo inusual, el lector se encuentra ante creaciones que cuestionan de forma constante las relaciones que las protagonistas mantienen con su familia o su pareja y que siempre se vuelven conflic- 
tivas. En esta novela en concreto, la conflictividad que se desarrolla entre la narradora y su marido parte de las dudas que a él se le plantean sobre el grado de veracidad de los hechos que ella narra. También se observa un conflicto entre el impulso creador de la narradora y el cuidado de sus hijos pequeños, que le impiden conseguir tiempo para escribir su novela. Igualmente, en Desierto sonoro se presenta un matrimonio en crisis que pronto se disolverá. Además de las relaciones conflictivas que mantienen con otros personajes y del tema de la maternidad, es frecuente que los personajes femeninos narren en primera persona apelando al carácter autoanalítico y confesional; «mujeres en tránsito, frágiles e inestables que referencian sus cuerpos, cuerpos invadidos (...) como línea argumental» (Alemany Bay, 2019: 321). Este rasgo narrativo se observa en diferentes ocasiones a lo largo de la novela. Cuando la protagonista comienza a narrar su vida como editora en Nueva York dice:

Escribía cartas a mis conocidos, les contaba sobre mis caminatas, sobre mis piernas enfundadas en unas medias grises, sobre mi cuerpo envuelto en un abrigo rojo, con hondos bolsillos. Escribía cartas sobre el viento frío que acariciaba esas piernas (...) Cuando alguien ha vivido solo durante mucho tiempo, el único modo de constatar que sigue existiendo es articular las actividades y las cosas en una sintaxis compartible, esta cara, estos huesos que caminan, esta boca, esta mano que escribe (Luiselli, 2019a: 12-13).

Sin embargo, cuando vive en México con su marido y sus dos hijos la forma de referenciar su cuerpo cambia de forma sustancial: «Nadie me esperaba en ninguna cama. Ahora sí. Sé que cuando entre hoy al cuarto de los niños, la bebé percibirá mi olor y se estremecerá en su cuna, porque algún lugar secreto de su cuerpo le enseña ahora a reclamar su parte de aquello que nos pertenece a las dos (...) Luego, cuando entre a mi cuarto, mi marido también reclamará su porción de mí» (Luiselli, 2019a: 27).

Alemany Bay (2019) señala además que quizás el fragmentarismo es habitual por tratarse de ficciones posmodernas. Las novelas caracterizadas por la narrativa de lo inusual suelen presentar unidades textuales breves que pretenden articular una materia a veces compleja. Este modo de organizar el texto va acompañado por digresiones, indagaciones o saltos espaciotemporales: «La narrativa de lo inusual se apoya en discursos breves — novela corta y cuento-, y en su fragmentariedad nos ofrece una visión renovada de la escritura de mujeres en México. Ficciones fragmentadas, como también los son los personajes, en las que lo cotidiano toma otro rumbo, una verosimilitud nueva, como pasaje hacia nuevas realidades» (Alemany Bay, 2019: 322). 
Otra característica reseñable de Los ingrávidos es la diversidad de referencias intertextuales que se insertan a lo largo del libro. Su recurrencia favorece la fragmentación, las múltiples historias y el aparente caos señalados por Alemany Bay (2019: 311) como elementos habituales en la narrativa de lo inusual. García-Valero (2019) apunta en este sentido a la novela Odio, de Díaz Enciso, donde la autora introduce voces de diferentes categorías artísticas, entre las que se encuentran relatos de Lewis Carroll, canciones de Morrissey o fragmentos del Paraíso perdido de Milton, lo que da como resultado un texto multiestratificado. Cabe recordar que el concepto de intertextualidad fue acuñado en 1969 por la teórica búlgaro-francesa Julia Kristeva. La noción aparece por primera vez en un apartado de su volumen Semiótica titulado «La palabra, el diálogo y la novela» relacionado con dos libros de Mijaíl Bajtín. En dicho apartado señala que «todo texto se construye como un mosaico de citas, todo texto es absorción y transformación de otro texto. En el lugar de la noción de intersubjetividad se instala la de intertextualidad, y el lenguaje poético se lee, al menos, como doble» (Kristeva, 1981: 190).

Yvette Sánchez (1999) considera por su parte que la creación literaria es una forma de coleccionar los textos previamente leídos. El material precedente necesita estructurarse en un nuevo entorno después de un ejercicio de selección y combinación, por lo que el proceso creativo apenas funciona sin lectura previa. Escribir significa, por tanto, incorporar lo leído - los textos anteriores coleccionados- en un texto nuevo. También advierte que los lectores y la crítica se deleitan cada vez más en acechar referencias a fuentes anteriores, pues «se ganan distinción, participan un poco en el nimbo de la autoridad creadora y pertenecen al círculo de los iniciados al aludir a textos canónicos» (Sánchez, 1999: 256).

En el caso de la novela de Luiselli, las referencias intertextuales aluden fundamentalmente a obras literarias en español y en inglés en las que en algunas ocasiones se reflexiona incluso sobre el ejercicio de la traducción, lo que se relaciona con otra de las características de la narrativa de lo inusual: la reinterpretación de textos canónicos. Encontramos un ejemplo de ello cuando la narradora y White, el chief editor, comentan el Cántico espiritual de san Juan de la Cruz:

¿Qué prefieres? — preguntó White, ¿«sonorous rivers» O «roaring torrents»? Ninguna de las dos.

Y qué tal lo de los valles: ¿«wooded valleys» 0 «bosky valleys»?

No sé, pero lo de «amorous gales» es horrible.

Tienes razón: «amorous breezes» (Luiselli, 2019a: 38-39). 
Entre las diversas voces que componen ese corpus literario que recoge la novela, destacan, además de san Juan de la Cruz, fragmentos y análisis sobre las creaciones literarias de Emily Dickinson, Federico García Lorca, Louis Zukofsky o Gilberto Owen. No obstante, la autora amplía de forma considerable la nómina de referencias en Desierto sonoro, donde además de incluir fragmentos de obras literarias de Walt Whitman, Nathalie Léger o Cervantes, presenta referencias de libros, fotografías de prensa y cotidianas, recortes, mapas, notas sueltas y reportes que se relacionan con la profesión de documentalista que ejercen la narradora y su marido, y atestiguan, entre otros aspectos, información relativa a la mortalidad de los niños migrantes que tratan de cruzar la frontera entre México y Estados Unidos.

Estos documentos se presentan en forma de capítulos, a los que denomina cajas (desde la I hasta la VII), correspondiéndose con el referente de las cajas de cartón que la narradora, su marido y sus hijos (un niño de él y una niña de ella) trasladan en su viaje en coche desde Nueva York hasta Arizona, durante el cual se entrelazan, asimismo, las noticias sobre la crisis migratoria, la historia de los apaches, una descripción de fotografías de Sally Mann, la letra de la canción Space Oddity de David Bowie, títulos de westerns como El sheriff de la quijada rota o Los tres implacables o la referencia al ballet Appalachian Song de Copland. Sin embargo, la referencia intertextual más relevante en Desierto sonoro la constituye el conjunto de Elegías para los niños perdidos que la narradora atribuye a la escritora ficcional Ella Camposanto (1928-2014), cuyo apellido hace referencia a los cementerios, un espacio narrativo recurrente en las obras de Luiselli que establece puentes entre el presente y el pasado. En Papeles falsos, por ejemplo, se refiere al cementerio de San Michele de Venecia para hablar de Ezra Pound o Joseph Brodsky, y también al de la ciudad de México, «el mismísimo camposanto en donde están las tumbas de los héroes nacionales Juárez, Miramón, Comonfort, Guerrero y Zaragoza» (Luiselli, 2017: 99).

La narradora de Desierto sonoro afirma que el libro de las elegías fue escrito originalmente en italiano y traducido después al español por Sergio Pitol (escritor, traductor y diplomático mexicano real que vivió entre 1933 y 2018). Esta forma de metaficción recuerda a Don Quijote de la Mancha, donde Cervantes presenta a un supuesto historiador musulmán llamado Cide Hamete Benengeli como autor de las aventuras de don Quijote y Sancho Panza, y cuya obra llega al lector a través de traducciones al español. Esta equiparación entre obras literarias tan alejadas en el tiempo no resulta extraña si se tiene en cuenta la relación que distintos autores como Mercedes Juliá (2010) o 
Esther Bautista Naranjo (2014) establecen entre la obra cumbre de Cervantes y la narrativa posmoderna.

La narradora de Desierto sonoro indica también que el libro de las elegías es la única obra de la escritora y que está basada vagamente en la histórica Cruzada de los Niños de 1212, en la que miles de menores viajaron a través de Europa o tal vez más allá. En la versión de Camposanto, la cruzada sucede tal vez entre Centroamérica y Norteamérica, pues los niños del libro se montan en «góndolas», una palabra que en Centroamérica se utiliza para designar a los vagones o los carros de los trenes de carga. A partir de la página 176, estas elegías se van intercalando con la voz de la narradora, y más adelante con la del hijo de su marido, un niño de diez años. Es decir, al igual que en Los ingrávidos, la novela se divide en dos voces fundamentales. La primera de ellas se corresponde con un personaje femenino que va desapareciendo progresivamente desde un punto de vista lingüístico para dar paso a una voz narradora masculina, y en este caso infantil, que conlleva una perspectiva diferente de los hechos.

Las noticias de los menores migrantes que emiten por la radio y la preocupación de la protagonista por ellos, así como las lecturas de las elegías y las historias sobre niños apaches que cuenta el padre durante el viaje en coche ejercen una influencia determinante en el niño que va a tomar la voz narradora: «Finalmente entendí por qué mamá se la pasaba pensando en los niños perdidos, y hablando sobre ellos, y por qué parecía estar cada día más lejos de nosotros. Los niños perdidos, todos ellos, eran mucho más importantes que nosotros (...) Eran como los Guerreros Águila de papá, tal vez incluso más valientes. Eran niños que estaban luchando y cambiando la historia» (Luiselli, 2019b: 292). A partir de ese momento, el niño toma la decisión de huir con su hermana de cinco años, la hija de la narradora, para buscar a dos niñas perdidas de ocho y diez años que habían cruzado la frontera a pie y se encontraban en un centro de detención en Texas. Eran hijas de Manuela, una amiga de su madre que le había pedido ayuda para traducir sus documentos del español al inglés y poder encontrar después un abogado que las defendiera ante una posible orden de deportación.

Durante el tiempo que los hermanos estuvieron perdidos, pasaron hambre, sufrieron el calor del desierto, cruzaron senderos, caminaron a lo largo de las vías del tren y viajaron en góndolas con el objetivo de llegar a Echo Canyon. A pesar de las duras condiciones, el niño se mantiene constante con la lectura de las elegías, continuando así con la sucesión de textos intercalados que ya había comenzado la narradora femenina, lo que recuerda asimismo a 
la estructura narrativa del Quijote. De esta forma, se va produciendo progresivamente una fusión entre el plano ficcional de las Elegías de los niños perdidos y el marco narrativo en el que se encuadran los niños protagonistas, hasta que finalmente confluyen en el capítulo «Sueña caballos»:

cuatro caras redondas nos miraban directamente desde el otro lado del viejo vagón del tren, tan reales que no pensé que fueran reales, pensé será posible o me estoy imaginando cosas, porque el desierto te traiciona, a esas alturas lo sabíamos muy bien tú y yo, y todavía no podía creer que fueran reales, aunque los cuatro niños estaban allí de pie frente a nosotros, dos niñas con trenzas largas, la mayor con un bonito sombrero negro, y luego dos niños, uno de ellos con un sombrero rosa (Luiselli, 2019b: 399).

Esta confluencia de marcos espaciotemporales se observa también en Los ingrávidos, donde se van aproximando de forma progresiva el presente de la narradora en México, donde vive con su marido y sus dos hijos, y la última etapa de Gilberto Owen en un departamento de Filadelfia en el que se instalan tres gatos a los que llama Cantos, Paterson y The. El comienzo de esta fusión se anuncia desde las primeras páginas, cuando la editora revela que les gusta pensar que en su casa hay un fantasma al que su hijo se refiere con el nombre de Consincara. El fantasma tira torres de libros, abre y cierra puertas y prende la estufa. A veces mece a la bebé mientras su madre escribe y ninguna de las dos siente miedo; sin embargo, el niño se asusta tanto que enseguida se acurruca en los brazos de su padre, quien le jura que solo era una broma.

Más adelante, el lector intuye que Consincara hace referencia a Owen, pues en un ejemplar de sus Obras que la editora toma prestado de la biblioteca hay una sección de fotografías entre las que se encuentra el rostro difuminado del poeta: «La frente amplia y un mechón de fleco rizado. Una nariz fina, casi un pico. La ceja ensombrecía un párpado inexistente, el ojo dormido, suave. Apenas un asomo del labio superior. Todo lo demás, negro. Un hombre casi sin rostro» (Luiselli, 2019a: 37), lo que se relaciona con las muchas muertes que Owen tiene a lo largo de la vida, momentos en los que todo da un giro, aunque sea imperceptible y no siempre se observen consecuencias inmediatas.

Al final de la novela, se observa que los tres felinos con los que convive Owen aluden a la narradora y sus dos hijos y que ambos planos se fusionan; el poeta llega a identificar incluso el zumbido de los mosquitos con las voces de los niños y siente la voz excitada del niño golpeándole la cara y exclamando que lo ha encontrado. Esta confluencia de espacios y tiempos comienza a 
materializarse a través de un temblor que hace caer los vasos desde las repisas y quebrarlos en diversos pedazos, en los que se refleja y multiplica la luz del único foco de la cocina, dando lugar a un espectáculo de luces bellísimo. A continuación, la madre y sus dos hijos se meten debajo de la mesa de la cocina. Cuando están seguros de que ya no hay temblores, salen del escondite y deambulan «como tres gatos por rincones oscuros (...) La bebé gatea por el piso tapizado de libros» (Luiselli, 2019a: 140). Sin embargo, se pone en duda que el temblor haya sucedido cuando la narradora dice que si vuelve a temblar se les pueden caer las cosas encima y el niño replica «¿cómo que si vuelve a temblar?» (Luiselli, 2019a: 141).

Además de la fusión de marcos espaciotemporales desde la perspectiva de experimentación lingüística, es preciso hacer referencia a otra de las características narrativas de lo inusual que se observa en Desierto sonoro. Se trata de la hibridación entre la ficción y los elementos autobiográficos (Alemany Bay, 2018: 10), pues la referencia al ballet de Copland o el interés y los conocimientos que muestra la autora sobre la crisis migratoria, entre otros aspectos, parecen tener una correspondencia con su vida real. Luiselli ha colaborado como libretista para el New York City Ballet y originalmente quería ser bailarina, aunque finalmente decidió concentrarse en la escritura. Asimismo, como mexicana y madre que vive en los Estados Unidos, no le resultaron indiferentes las noticias sobre el incremento de niños refugiados durante el verano de 2014. Comenzó a trabajar en una corte de inmigración en Nueva York, donde se le asignó la tarea de ayudar a los niños refugiados con un cuestionario elaborado por un grupo de abogados migratorios estadounidenses. Primero les tenía que realizar las preguntas en español y después traducir sus respuestas al inglés. Dependiendo de lo que respondieran, podrían tener algún tipo de protección legal, así como un futuro en los Estados Unidos. Sin embargo, Luiselli se dio cuenta de que no era posible encuadrar las complejas historias de los niños en las casillas preestablecidas.

Como resultado de este trabajo, la escritora publicó en el año 2016 un libro de ensayos titulado Los niños perdidos, es decir, la obra aparece mientras se desarrolla un contexto particularmente crítico entre el país de origen de Luiselli, México, y la patria donde reside, los Estados Unidos (v. Luiselli, 2019c). Mientras la campaña presidencial estadounidense entraba en su recta final, la relación entre ambos países se convirtió en una de las principales plataformas de la candidatura de Donald Trump, quien se refirió a los mexicanos como «violadores, ladrones y asesinos» e incentivó la construcción de un muro a lo largo de la frontera (Anderson, 2019: 10-11). Esta temática vinculada 
con la crisis migratoria presenta continuidad en la novela Desierto sonoro, cuyo título original es Lost Children Archive:

En la radio escuchamos un largo reportaje sobre los niños en la frontera. Habíamos decidido no escuchar más noticias al respecto, o al menos no mientras nuestros hijos estuvieran despiertos. Pero los últimos acontecimientos, y en particular la historia de los niños que están a punto de ser deportados cerca de Roswell, nos impiden ignorar el mundo que se extiende más allá de nuestro coche (Luiselli, 2019b: 212).

Es posible afirmar, por tanto, que la narrativa ficcional de Luiselli presenta elementos autobiográficos, lo que constituye una de las características narrativas de lo inusual. Sin embargo, la escritora advierte en una entrevista que la realidad presente en sus libros no se relaciona con la autoficción, algo que le interesa muy poco. Elabora sus obras con lo que tiene al alcance - su léxico familiar, la comunidad con la que trabaja o la realidad política- y todo ello se va trenzando de modo ficcional (Maristain, 2020). Es decir, extrae material narrativo de su experiencia con la realidad inmediata sin llegar a la autoficción: «Trenzo siempre de manera ficcional, pero hay ciertas fibras que vienen de mi vida personal y mi experiencia» (Guimón, 2019).

\section{Conclusiones}

A lo largo del artículo se han presentado las principales características de una nueva modalidad discursiva de lo insólito a la que Carmen Alemany Bay ha denominado «narrativa de lo inusual»; una propuesta que, por reciente, aún no se incluye entre las principales categorías de los géneros literarios de la literatura no mimética, aunque sí comparte algunos de sus elementos narrativos con lo extraño, lo fantástico, lo maravilloso o el realismo mágico, como se ha podido comprobar en el apartado dedicado a la introducción.

Aunque colinda con lo extraño, lo inusual presenta estrategias lingüísticas diferentes y no se inspira en casos anómalos que quiebren las bases científicas de nuestro mundo, sino en una realidad actual y cotidiana que es vivida como extraña por los personajes. También se ha observado que se aleja de lo fantástico porque los acontecimientos de los relatos de lo inusual no cruzan la frontera de lo imposible. Asimismo, se diferencia de los relatos maravillosos, puesto que en estos no encontramos espacios cotidianos que reflejen nuestro mundo, sino mundos que se rigen por leyes naturales diferentes y donde tienen 
cabida acontecimientos que no suceden en nuestra realidad, como las hadas o los encantamientos. Finalmente, se han expuesto las diferencias que presenta en relación con el realismo mágico, entre las que destaca la ausencia de referencias a sustratos indígenas precolombinos o la presencia de entornos sobrenaturales, que se entienden como hipérboles, alucinaciones o ensoñaciones de las protagonistas, no como lógicas basadas en leyendas, religiones o fenómenos de la naturaleza, más propias del realismo mágico. En definitiva, este conjunto de diferencias que presenta la narrativa de lo inusual respecto al resto de modalidades de lo insólito justifica su estudio como categoría independiente.

Una vez determinada la autonomía de lo inusual, se han seleccionado dos novelas de la escritora mexicana Valeria Luiselli para observar de forma más precisa, y en un contexto concreto, de qué manera se materializan las características que constituyen esta categoría como modalidad discursiva independiente de otras modalidades de lo insólito. Las dos obras elegidas, Los ingrávidos y Desierto sonoro, son quizás los dos libros de la autora en los que las particularidades narrativas de lo inusual se revelan de forma más significativa, especialmente en el primero de ellos, pues Desierto sonoro no oscila tanto en la línea que divide lo posible de lo imposible, sino que se afinca más en el primer término; asimismo, no se trata de una novela corta o un relato, géneros donde la narrativa de lo inusual se desarrolla con mayor fluidez.

La elección de una u otra obra, como se puede observar, no resulta tarea sencilla, pues no siempre presentan unas fronteras claras que delimiten de forma exacta el espacio correspondiente a cada una de las modalidades de lo insólito. Sin embargo, se hace necesario acotar el corpus para alcanzar un análisis más preciso de las particularidades de la narrativa de lo inusual, asumiendo el riesgo de dejar al margen algunos elementos narrativos interesantes que se muestran en otros libros que no hemos seleccionado. Asimismo, es posible que las obras elegidas no presenten una correspondencia exacta con la categoría de lo inusual.

A lo largo del análisis de las novelas, se ha hecho hincapié fundamentalmente en el estudio del espacio, el tiempo y la intertextualidad, constituyendo de esta manera un eje que atraviesa diferentes características narrativas de lo inusual. En relación con los marcos espaciotemporales, se ha observado que Valeria Luiselli recurre al léxico de la tradición fantástica y emplea el concepto de fantasma para hablar de temporalidades que se cruzan, sin que ello signifique que en Los ingrávidos haya fantasmas. También se ha llamado la atención sobre el pequeño árbol seco como objeto que, sin ser mágico, promueve desde una perspectiva psicológica el acceso de la protagonista a otra 
vida posible que no era la suya, sino la de Owen, lo que se traduce en el plano enunciativo como la alternancia de diferentes tiempos narrativos.

Asimismo, los post-its que se van cayendo de las ramas del árbol seco, y cuyos textos se van intercalando con las voces narradoras de la editora y de Owen, potencian el carácter fragmentario que presenta la novela; una manera de escribir en corto aliento que hace eco de los pocos intervalos de tiempo de los que dispone la protagonista para dedicar a su novela. Se ha puesto el foco también en la confluencia de planos espaciotemporales tanto en Los ingrávidos como en Desierto sonoro, observándolo únicamente desde la perspectiva del plano lingüístico y enunciativo, pues se trata de una forma inusual de presentar la realidad a través del lenguaje y no de un fenómeno propio de la literatura fantástica, en la que se transgreden nuestros códigos sobre el funcionamiento de lo real.

En cuanto a los principales espacios narrativos, se ha hecho referencia, por un lado, al metro, donde la autora se encuentra con el fantasma de Owen, al que se ha observado desde el concepto de no lugar acuñado por Marc Augé. Al igual que los aeropuertos, las estaciones ferroviarias o los supermercados, el espacio del metro se presenta como un punto de tránsito; forma parte de esa red de medios de transporte que constituye un mundo prometido a la individualidad, lo provisional y lo efímero: «La sobremodernidad es productora de no lugares, es decir, de espacios que no son en sí lugares antropológicos y que, contrariamente a la modernidad baudeleriana, no integran los lugares antiguos: éstos, catalogados, clasificados y promovidos a la categoría de "lugares de memoria", ocupan allí un lugar circunscripto y específico» (Augé, 2000: 83). Por otro lado, se ha llamado la atención sobre otros espacios, también urbanos, que inducen a la reflexión y al encuentro con las voces del pasado. Se trata de los cementerios, los parques y las azoteas. El que toma más relevancia en Los ingrávidos es la azotea donde la protagonista encuentra la maceta. Luiselli presenta los espacios elevados como lugares que promueven el ejercicio del pensamiento; por lo tanto, no resulta extraña la elección de una azotea como lugar en el que se origina el cruce espaciotemporal entre la editora y el poeta desde una perspectiva psicológica.

De este modo, observamos que en la narrativa inusual de Luiselli adquiere un peso significativo el cruce de marcos espaciotemporales y se sirve para ello de diferentes recursos. En el caso de Los ingrávidos alude al concepto de fantasma, o afantasmamiento, para hablar de personajes del pasado o diluir las voces narrativas. También recurre a espacios $u$ objetos sugestivos como la azotea o el árbol seco para impulsar desde ahí la multiplicidad de 
voces narrativas, sin olvidar el protagonismo que presenta el espacio del metro; una imagen característica de la vida cotidiana de la protagonista, un punto de tránsito prometido a la individualidad y lo efímero, como indica Marc Augé y, por ende, un espacio vinculado con la literatura posmoderna.

En cuanto a la intertextualidad, se ha observado que las referencias incluidas en Los ingrávidos aluden fundamentalmente a obras literarias en inglés y en español en las que en algunas ocasiones se reflexiona sobre el ejercicio de la traducción. Sin embargo, Luiselli amplía de forma significativa el número de referencias intertextuales en Desierto sonoro, donde presenta, además de alusiones a textos literarios, fotografías, mapas o reportes. Sin embargo, la referencia intertextual más relevante de la novela es el conjunto de Elegías para los niños perdidos, que la narradora atribuye a una escritora ficcional -Ella Camposanto-, dando lugar, de esta manera, a una forma de metaficción que recuerda a Don Quijote de la Mancha. Las elegías se irán sucediendo a lo largo del libro hasta que ambos mundos ficcionales confluyan, como sucede en Los ingrávidos con el plano presente en el que se mueve la autora y los últimos años de vida de Gilberto Owen.

Cabe observar, asimismo, que ambas confluencias se vinculan con creaciones literarias o escritores del pasado, lo que se podría equiparar al ejercicio de la imaginación que desarrolla un individuo en el acto de la lectura y que lo aproxima a otras vidas y lugares. En Los ingrávidos, la editora llevaba tiempo buscando información sobre Owen y leyendo sus libros hasta que poco a poco comienza a existir habitada por otra vida posible. Asimismo, el interés que producen las elegías en el personaje infantil de Desierto sonoro termina por fusionar la ficción del libro de Ella Camposanto con su realidad.

Además de observar el espacio, el tiempo y la intertextualidad, en el estudio de ambas novelas se han incluido reflexiones sobre las relaciones conflictivas que las protagonistas mantienen con su familia o su pareja, las referencias a su cuerpo como línea argumental y la hibridación entre la ficción y los elementos autobiográficos, lo que constituye una mirada sobre la realidad desde una perspectiva femenina. Sin embargo, la particular visión femenina que caracteriza la narrativa de lo inusual no se observa de forma completa en las dos novelas analizadas, ya que, tanto en Los ingrávidos como en Desierto sonoro, una voz masculina va tomando el relevo de la voz de la protagonista. En el primer caso se corresponde con la de Owen, mientras que en el segundo la voz pertenece a un niño de diez años, lo que demuestra que las clasificaciones de la literatura —en este caso no mimética — no siempre permiten hablar de una coherencia estética completa. 
Tampoco cabría afirmar que el lenguaje de lo inusual se da de forma exclusiva en este tipo de narrativa, ya que el corte intimista o los rasgos alegóricos se pueden hallar en otras corrientes literarias. No obstante, la autoría femenina, los elementos fantásticos de carácter metafórico, el encaje con las leyes naturales de la realidad empírica y la codificación de una realidad a través de un discurso que recurre a fenómenos sobrenaturales para expresar el interior de las protagonistas constituyen sin duda una narrativa con entidad propia que comienza con el nuevo siglo y que acabará incluyéndose entre las categorías de la literatura no mimética si el debate académico lo considera adecuado.

\section{BiBLIOGRAFÍA}

Aвate, Sandro (1997): «A medio siglo del realismo mágico: balance y perspectivas», Anales de Literatura Hispanoamericana, núm. 26/1, pp. 145-159.

Alemany Bay, Carmen (2016): «Narrar lo inusual. Bestiaria vida de Cecilia Eudave y El animal sobre la piedra de Daniela Tarazona», Romance Notes, núm. 56/1, pp. 131-141.

— (2018): «Prólogo», en Cecilia Eudave, Bestiaria vida, Eolas Ediciones, León, pp. 7-13.

— (2019): «¿Una nueva modalidad de lo insólito en tiempos posmodernos? La narrativa de lo inusual», en Natalia Álvarez Méndez y Ana Abello Verano (eds.), Realidades fracturadas. Estéticas de lo insólito en la narrativa en lengua española (19802018), Visor Libros, Madrid, pp. 307-324.

Anderson, Jon Lee (2019): «Prólogo» (trad. Eduardo Rabasa), en Valeria Luiselli, Los niños perdidos (Un ensayo en cuarenta preguntas), Sexto Piso, Madrid, pp. 9-12.

Augé, Marc (2000): Los no lugares. Espacios del anonimato, trad. Margarita Mizraji, Gedisa, Barcelona.

BAUtista NARAnjo, Esther (2014): El mito de don Quijote en la novela posmoderna y su reescritura paradigmática en City of Glass (1985), de Paul Auster, Academia del Hispanismo, Vigo.

Cirlot, Juan Eduardo (2018): Diccionario de símbolos, Siruela, Madrid.

García-Valero, Benito (2019): «Para una teoría de lo inusual. Procedimientos lingüísticos, planteamientos estéticos», en Natalia Álvarez Méndez y Ana Abello Verano (eds.), Realidades fracturadas. Estéticas de lo insólito en la narrativa en lengua española (1980-2018), Visor Libros, Madrid, pp. 325-338.

- (2020): «Los trazos en el cuerpo, el cuerpo a trazos. Imaginario, lirismo y alteridad interior en la narrativa de lo inusual escrita por mujeres», Brumal. Revista de investigación sobre lo fantástico, núm. 8/1, pp. 17-34.

Guimón, Pablo (2019): «Valeria Luiselli: “Son las voces de mujer las que me activan, me intrigan y me emocionan"», disponible en <https:/ / elpais.com/cultu$\mathrm{ra} / 2019 / 08 / 30 /$ babelia/1567187419_315431.html > [17-11-2020]. 
Juliá, Mercedes (comp.) (2010): Don Quijote y la narrativa posmoderna, Servicio de Publicaciones, Universidad de Cádiz.

KRISTEVA, Julia (1981): Semiótica 1, trad. José Martín Arancibia, Editorial Fundamentos, Madrid.

LicATA, Nicolas (2020): «Doble, fantasma y madre: vasos comunicantes en Los ingrávidos, de Valeria Luiselli», Brumal. Revista de Investigación sobre lo Fantástico, vol. VIII, núm. 1, pp. 71-92.

Luiselli, Valeria (2011a): «Todos morimos de algún modo muchas veces», disponible en <https: / / www.youtube.com/ watch?v=VDedWAMePgg $>$ [17-10-2020].

— (2011b): «Entrevista con Valeria Luiselli», disponible en <https:/ / www.youtube. $\mathrm{com} /$ watch?time_continue $=277 \& \mathrm{v}=$ _rsb42Po5J8\&feature $=$ emb_logo $>\quad[17-10-$ 2020].

- (2014): La historia de mis dientes, Sexto Piso, Madrid.

- (2017): Papeles falsos, Sexto Piso, Madrid.

- (2019a): Los ingrávidos, Sexto Piso, Madrid.

- (2019b): Desierto sonoro, Sexto Piso, Madrid.

- (2019c): Los niños perdidos (Un ensayo en cuarenta preguntas), Sexto Piso, Madrid.

Maristain, Mónica (2020): «Valeria Luiselli: “Me interesa poquísimo la autoficción"», disponible en <https: / / www.infobae.com/ cultura/2020/04/22/valeria-luiselli-me-tuve-que-volver-feminista-a-chingadazos / > [17-10-2020].

Quevedo, Francisco de (1968): Obras completas, I, ed. José Manuel Blecua, Planeta, Barcelona.

Roas, David (2011): Tras los limites de lo real. Una definición de lo fantástico, Páginas de Espuma, Madrid.

SÁNCHEZ, Yvette (1999): Coleccionismo y literatura, Cátedra, Madrid.

Usi, Eva (2013): «Los ingrávidos, de Valeria Luiselli, aclamada en Berlín», disponible en <https: / / www.dw.com/es/los-ingr\%C3\%A1vidos-de-valeria-luiselli-aclamada-en-berl\%C3\%ADn/a-16878999> [17-10-2020]. 